\title{
Mediterranean moray eel Muraena helena (Pisces: Muraenidae): biological indices for life history
}

\author{
Sanja Matić-Skoko ${ }^{1, *}$, Pero Tutman ${ }^{1}$, Mirela Petrić ${ }^{2}$, \\ Daria Skaramuca ${ }^{3}$, Domagoj Đikić ${ }^{4}$, Duje Lisičić ${ }^{4}$, Boško Skaramuca ${ }^{3}$ \\ ${ }^{1}$ Institute of Oceanography and Fisheries, PO Box 500, Šetalište Ivana Meštrovića 63, 21000 Split, Croatia \\ ${ }^{2}$ University of Split, Center of Marine Studies, Livanjska 5/III, 21000 Split, Croatia \\ ${ }^{3}$ Faculty of Aquaculture, University of Dubrovnik, Ćire Cari a 4, 20000 Dubrovnik, Croatia \\ ${ }^{4}$ Faculty of Natural Sciences and Mathematics, Department for Animal Physiology, University of Zagreb, Rooseveltov trg 6 , \\ 10000 Zagreb, Croatia
}

\begin{abstract}
This paper presents the first published data on age, growth and reproduction of the moray eel Muraena helena in the Mediterranean Sea. A total of 193 individuals of M. helena were sampled by longlines at depths from 5 to $80 \mathrm{~m}$ in the southern Adriatic Sea. The length and weight of individuals ranged from 27.5 to $121.0 \mathrm{~cm}$ and from 116.1 to $3680.0 \mathrm{~g}$, respectively. Age readings from annual zones of $M$. helena otoliths revealed the presence of age groups 2 to 12 . The von Bertalanffy growth function (VBGF) for the sampled population had the following parameters: $L_{\infty}=162.70 \mathrm{~cm}, k=0.089 \mathrm{yr}^{-1}$ and $t_{0}=-0.660 \mathrm{yr}$. Females dominated the total male:female ratio (0.35:1.00) and, together with immatures, were more frequent in shallow coastal waters. The greatest increase in gonadosomatic index occurred in summer, while condition factor was the lowest in winter. The ovaries of moray eels mostly contained oocytes in a pre-vitellogenic or vitellogenic stage and males with testes at maturation stage were observed at the beginning of July. The absence of males and ripe or spent females in the inshore coastal waters suggests that moray eels leave this region in summer to spawn, most likely in the south Adriatic Pit at a depth below $600 \mathrm{~m}$.
\end{abstract}

KEY WORDS: Moray eel · Muraena helena $\cdot$ Age $\cdot$ Growth $\cdot$ Reproduction · Adriatic Sea

\section{INTRODUCTION}

Moray eels (Muraenidae) are a family of approximately 200 predatory reef fish species found in every tropical and temperate seas, but they are not well studied because of their cryptic habitats and occasionally aggressive behaviour that make them difficult to collect (Reece et al. 2010 and references therein). Consequently, basic information on their biology and ecology is scarce. A few papers have been published about behavioural ecology (Abrams et al. 1983), spawning (Ferraris 1985), comparative gonad morphology and sexuality (Fishelson 1992); however, there are no data concerning spatial and temporal features of spawning, or about age, growth and reproductive biology of moray eels. Recently, Jiménez et al. (2007) confirmed separation of $\mathrm{Mu}$ raena augusti from $M$. helena using a multidisciplinary approach including biometric, ecological and molecular analyses.

Moray eels have a long pelagic larval interval up to 2 yr (Bishop \& Torres 1999, Reece et al. 2010) and, being poor swimmers as juveniles and adults, they maintain high site fidelity to a few square meters of reef (Böhlke et al. 1989). They adopted biting as an alternative prey capture strategy instead of sucking and this could be related to their success as predators in the confined spaces of reef crevices (Mehta \& Wainwright 2007, 2008). In general, adult moray eels are night carnivores which mainly feed on benthic 
fishes, cephalopods and crustaceans (Göthel 1992). Their diet probably depends on fish size and reflects differences in prey availability, as was previously found for the closely related species Conger conger (Cau \& Manconi 1983). Piscivores like moray eels affect the post-settlement survivorship of some fish species; thus such predation may have an important role in structuring local reef-fish assemblages (Carr \& Hixon 1995).

Muraena helena is an eastern Atlantic-Mediterranean moray eel whose range extends north to the British Isles and south to Senegal and Cape Verde (Smith \& Böhlke 1990); it is also found in the Canary Islands, Madeira and Azores (Randall \& Golani 1995). This territorial species is found on rocky bottoms, commonly lurking in holes and writhing through crevices or under rocks during the day. It is more active during night, when moray eels leave their shelter, but just for a short time and only in vicinity of their own holes. The species is distributed from shore to a depth of $800 \mathrm{~m}$, rarely or infrequently shallower than $50 \mathrm{~m}$ and commonly at depths of 100 to $300 \mathrm{~m}$ (Jiménez et al. 2007).

The eastern coastal region of the southern Adriatic Sea includes shallow waters around the outer islands but reaches depths of up to $1330 \mathrm{~m}$ in the south Adriatic Pit (Fig. 1). It is characterized by rocky bottoms and therefore represents an ideal habitat for Muraena helena. Two moray eel species are found in the Adriatic: the very rare Gymnothorax unicolor and the more common M. helena (Jardas 1996). In the last

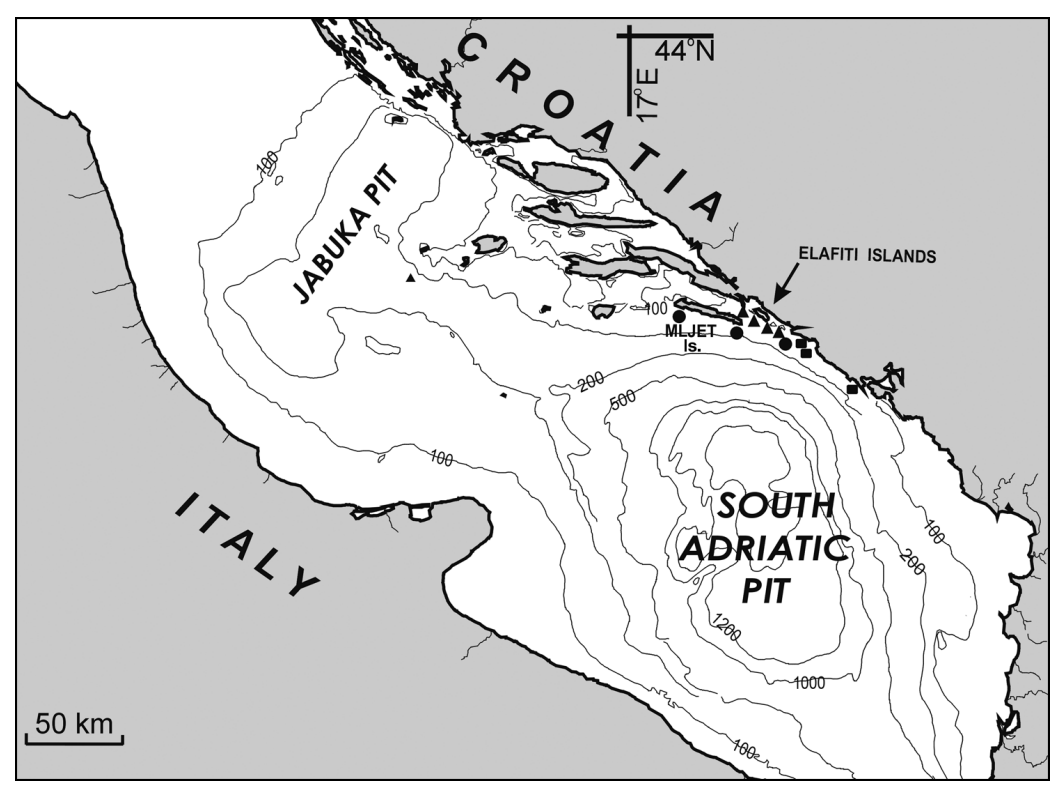

Fig. 1. The study area in the southern Adriatic Sea with sampling locations

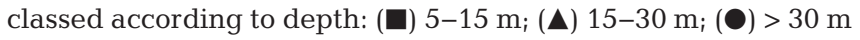

decade, $M$. helena has become very frequent and is now one of the species with pronounced dominance in the last decade among the fish communities of the outer islands in the middle and southern Adriatic, as is evident from longline catches of artisanal fishers (Matić-Skoko et al. 2009).

Although it is well known and probably plays a significant ecological role in Mediterranean rocky benthic communities as a part-time resident top predator (Hixon 1991), Muraena helena is still a poorly studied species and there are no published data on its biology and ecology. The present study was conducted to examine age, growth and reproductive biology of the Mediterranean moray eel $M$. helena from specimens captured along the eastern Adriatic coast.

\section{MATERIALS AND METHODS}

A total of 193 individuals of Muraena helena were caught on monthly basis between October 2009 and December 2010 in the southern Adriatic with bottom longlines at depths of 5 to $80 \mathrm{~m}$ (shallow costal waters around Dubrovnik: 5 to $15 \mathrm{~m}$; Elafiti Archipelago: 15 to $30 \mathrm{~m}$; islands of Mljet and Sveti Andrija: 30 to $80 \mathrm{~m}$ ), depending on the coastal configuration (Fig. 1). Approximately 16 individuals (range 12 to 46 ) were examined per month. For each fish, the total length (TL) was measured (precision $0.1 \mathrm{~cm}$ ), the total body weight $(W)$ was recorded (precision $0.1 \mathrm{~g}$ ), and the sagittal otoliths were removed, cleaned and stored dry for further examination. Before the age reading process, otolith length (OL) was measured (precision $0.1 \mathrm{~mm}$ ) at the longest axis and otolith mass $(\mathrm{OM})$ was weighed (precision $0.1 \mathrm{~g}$ ). For testing the sex ratio a simple Chi-square test was used. The size frequency distributions $(5 \mathrm{~cm}$ length classes) between sexes were determined. All data were tested for normality and homogeneity of variances.

The length-weight relationship was described by the equation $W=a \mathrm{TL}^{b}$ (Ricker 1975). The variation in $b$ value from 3 was tested by the 1-sample $t$-test. Analysis of covariance (ANCOVA) was used to test for differences in sizeweight relationship between the sexes, considering fish length as a covariate. The condition factor (CF) was calculated from the equation: $\log W=b \log$ $\mathrm{TL}+\log a$ (Ricker 1975). 


\section{Age analysis}

Age was determined by interpreting the growth rings on the otoliths. Otoliths were fastened to a slide and then sanded using $30 \mu \mathrm{m}$ sandpaper and $0.3 \mu \mathrm{m}$ Buehler Alpha MicroPolish alumina and polished to facilitate the observation of the opaque and translucent zones. All otoliths were observed immersed in water against a black background using a stereo microscope at 3.75 magnification. Age was determined by counting growth rings on the posterior otolith region. All otoliths were read independently by 3 experienced researchers, with age assigned when at least 2 of the readers were in agreement. The index of average percent error (IAPE) (Beamish \& Fournier 1981) as well as the mean coefficient of variation (CV) (Chang 1982) was calculated to estimate the relative precision between readings. Low values of these indices indicated a good precision of age estimation.

The sample available for age and growth studies consisted of 179 individuals $192.8 \%$ readable otoliths). A ring mark was considered as the outer edge of the opaque zone. Opaque and translucent zones exhibited an alternating pattern. The total number of translucent zones was recorded in order to assign an estimated age to the Mediterranean moray eel specimens. The periodicity of opaque zone formation was examined by edge-type analysis (Palazón-Fernandez et al. 2010). The marginal edge of each otolith was examined and classified as opaque or translucent and percentages of otoliths with opaque and translucent margins were plotted by month of capture in order to determine periodic trends in zone formation. The marginal increment was measured along the long axis of each otolith (precision $0.01 \mathrm{~mm}$ ) and used to validate the ageing.

Relationships between OL or OM and fish age $(t)$ were determined applying a simple linear regression model. The main objective was to obtain a predictive equation that would allow simple determination of fish age from otolith morphometry.

Length-at-age was described by the von Bertalanffy growth function (VBGF), TL $=L_{\infty}\left(1-\mathrm{e}^{-k\left(t-t_{0}\right)}\right)$, where TL is total length at age $t_{1} L_{\infty}$ is asymptotic length, $k$ is the body growth coefficient and $t_{0}$ is theoretical age at zero length (Beverton \& Holt 1957). The von Bertalanffy growth parameters were estimated using a non-linear least square procedure, through a Gauss-Newton algorithm. The multivariate Hotelling's $T^{2}$-test was used to compare growth parameters obtained for males and females. Kolmogorov-Smirnov 2-sample test was used to analyze both age and size frequency distributions of both sexes. The mean lengths of males and females in the same age classes were tested using the $t$-test, after testing data for normality (Kolmogorov-Smirnov test of normality). Taylor's (1960) equation was used to calculate longevity from parameters obtained by VBGF: $A_{0.95}=[2.9957 / k]+t_{0}$, where $A_{0.95}$ is the lifespan or age required to reach $95 \%$ of the final length $\left(L_{\infty}\right)$, and $t_{0}$ and $k$ are von Bertalanffy growth parameters, in order to confirm that obtained ages from otolith reading were realistic.

\section{Reproductive analysis}

Sex and maturity stages (immature, premature and mature) of the Mediterranean moray eel were determined by direct visual observation of the gonads. Individuals without developed gonads were classified as immature. Premature specimens were distinguished by wrinkled or smooth gonad surface, a morphological structure distinctive for females and males, respectively. Mature females were easily recognized by big, orange eggs and mature males by big, white and tight testes. The gonadosomatic index was calculated as GSI $=\left(W_{\mathrm{g}} / W\right)^{*} 100$, where $W_{\mathrm{g}}$ is the gonad weight. For the estimation of mean length at $50 \%$ maturity, a percentage of the mature individuals by size class was used. For histological analysis of the gonadal tissue, a subsample of 39 individuals (22 male, 12 female and 5 immature) collected seasonally throughout a 1 -yr period was used. Tissue sections were fixed in Bouin solution and processed for routine histological preparation. The tissue was dehydrated in a graded ethanol series (from 70 to $100 \%$ ), cleared in xylene and embedded in paraffin. Histological sections were cut at $5 \mu \mathrm{m}$, stained with haematoxylin-eosin and then mounted permanently for further microscopic analysis. The terminology used in the histological description of gonad developmental stage followed criteria of Wallace \& Selman (1981) and Grier (1981).

Significant differences in CF and GSI were determined by 1-way analysis of variance (ANOVA) followed by a Tukey test.

\section{RESULTS}

A total of 193 individuals of Muraena helena were sampled, namely 48 immature, 106 female and 39 male specimens. The male:female ratio for all fish combined was $0.35: 1.00$ and it differed statistically significant from the expected 1:1 $\left(\chi^{2}=35.5 ; \mathrm{p}<0.05\right)$. 


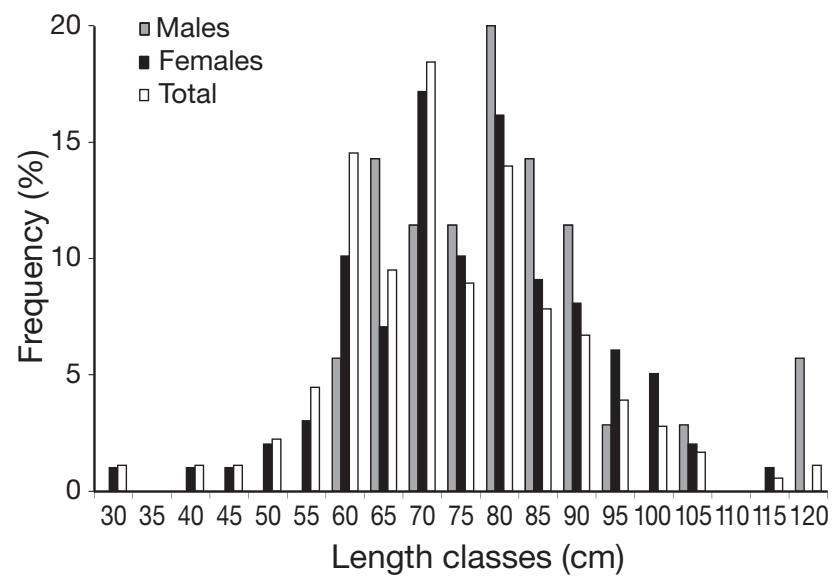

Fig. 2. Muraena helena. Length $(\mathrm{cm})$ frequencies of males, females and the total sample of Mediterranean moray eels from the Adriatic Sea

TL of all fish ranged from 27.5 to $121.0 \mathrm{~cm}$ (Fig. 2), with an average TL of $73.51 \mathrm{~cm}( \pm 14.965 \mathrm{SD}) . W$ ranged from 116.1 to $3680.0 \mathrm{~g}$, with an average $W$ of $975.26 \mathrm{~g}( \pm 666.811)$. The length frequency distribution of the total sample exhibited one mode at $70 \mathrm{~cm}$ (Fig. 2). Immature individuals ranged from 31.5 to $78 \mathrm{~cm}$, with an average TL of $62.55 \mathrm{~cm}( \pm 9.425)$. Adult males ranged from 60.0 to $121.0 \mathrm{~cm}$, with an average TL of $80.00 \mathrm{~cm}( \pm 14.138)$, while females ranged from 27.5 to $113.1 \mathrm{~cm}$, with an average TL of $76.38 \mathrm{~cm}$ $( \pm 14.841)$. The size frequency distributions of males and females were not significantly different (2-sample $t$-test, $\mathrm{p}=0.203$ ). Females were found at all sampling locations (at depth of 5 to $80 \mathrm{~m}$ ), unlike immatures and males, which dominated in inshore (depth $\sim 5 \mathrm{~m}$ ) and offshore waters (depth $>30 \mathrm{~m}$ ), respectively (Fig. 3).

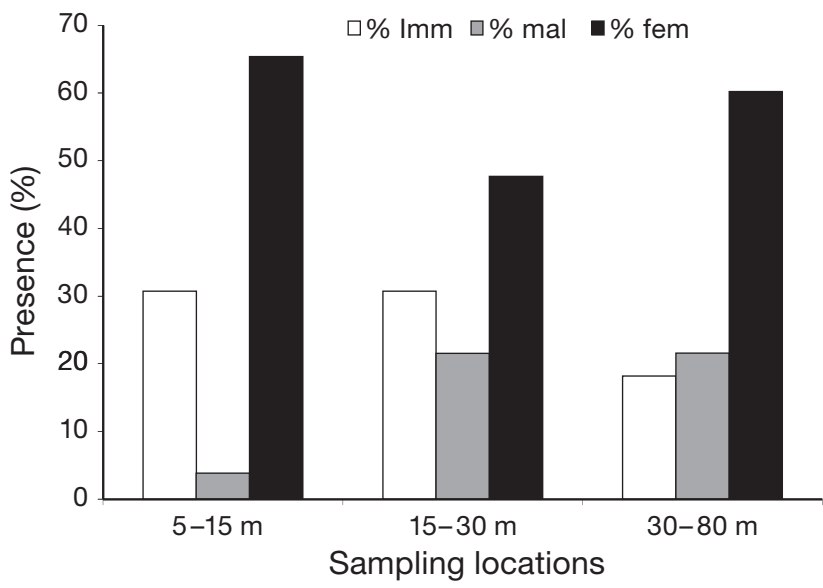

Fig. 3. Muraena helena. Vertical distribution of immature, male and female Mediterranean moray eels from sampling locations classed according to depth in the southern Adriatic Sea
The calculated length-weight equation for the whole sample was $W=0.0056 \times \mathrm{TL}^{2.776}\left(\mathrm{R}^{2}=0.817\right)$. This relationship for males was described by the parameters $a=0.0062$ and $b=2.764\left(\mathrm{R}^{2}=0.800\right)$ and for females by the parameters $a=0.0116$ and $b=$ $2.612\left(\mathrm{R}^{2}=0.764\right)$. The variations in $b$ values from 3 were statistically significant both for males ( $t$-test, $\mathrm{p}=0.001)$ and females $(t$-test, $\mathrm{p}=0.001)$. Analysis of covariance revealed significant differences between sexes (ANCOVA, $\mathrm{p}<0.0005$ ). The relative $\mathrm{CF}$ ranged from 0.88 to 3.16 for the female moray eels. There were no significant mean differences among seasons (1-way ANOVA, p > 0.05); however, CF was the lowest in winter (Fig. 4).

\section{Age analysis}

Otoliths of Muraena helena displayed well-defined alternating opaque and translucent zones under reflected light (Fig. 5). The IAPE of ring counts for each reader did not differ greatly, and was slightly lower for the first author (2.36) than for the second (2.48) and third (2.51). The precision of the age estimates $(\mathrm{CV})$ was 1.1. A distance measurements analysis revealed that the first regular, continuous ring appeared at a distance of $1.08 \mathrm{~mm}( \pm 0.047 \mathrm{SD})$ from the otolith nucleus. The formation of growth increments followed a seasonal pattern (Fig. 6); the opaque zones began to develop during winter months and they were completely formed in summer, which was coincident with estimated spawning period. The proportion of otoliths with opaque margins was the highest (>60\%) in August and September. The translucent zones were laid down mainly in the autumn-winter period, and our data suggest that 1 opaque and 1 translucent zone are laid down per

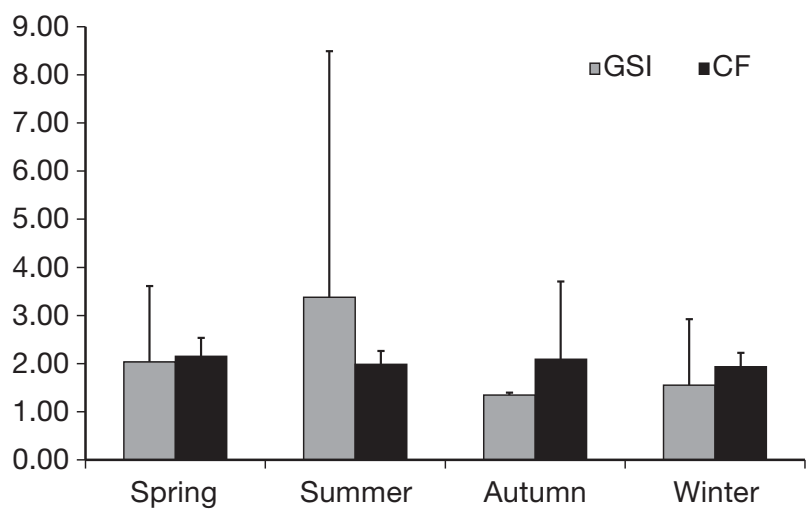

Fig. 4. Muraena helena. Seasonal variation of the relative condition factor (CF) and gonadosomatic index (GSI) of Mediterranean moray eels from the Adriatic Sea 


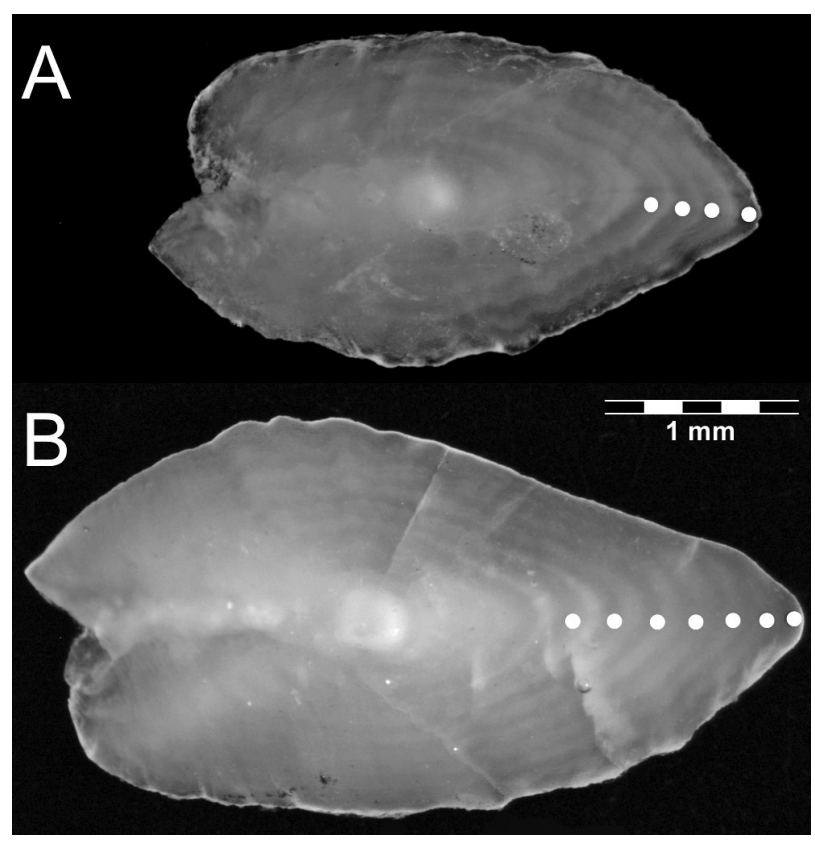

Fig. 5. Muraena helena. Otoliths of from the Adriatic Sea: (A) a $4 \mathrm{yr}$ old individual (length: $59.0 \mathrm{~cm}$; weight: $420.4 \mathrm{~g}$ ); (B) a $7 \mathrm{yr}$ old individual (length $78.0 \mathrm{~cm}$; weight: $803.6 \mathrm{~g}$ ). White dots indicate yearly growth rings. Magnification: 3.75

year. Moreover, the monthly mean marginal increment showed a single maximum in August (Fig. 6) and confirmed the formation of 1 annulus per year.

The age analysis revealed 11 age classes and the presence of age groups 2 to 12 , with only 2 individuals in the $2^{+}$group. The oldest males and females of Muraena helena were estimated to be 12 yr old. Predominance of age classes $6^{+}$and $7^{+}$in the total catch (44.1\% individuals) was observed. There was some overlapping of individuals with the same lengths, especially for the individuals with higher TL. The pooled length-at-age data for $M$. helena is given in Table 1. Females were the most numerous in the middle 3 age classes, represented by 16.2, 17.2 and $24.2 \%$ for classes $5^{+}, 6^{+}$and $7^{+}$, respectively. Males were the most numerous in $6^{+}$and $7^{+}$age classes (equally represented by $28.6 \%$ ) and their number declined in all subsequent classes. The younger age classes $\left(2^{+}\right.$and $\left.3^{+}\right)$were represented by only few female specimens. Age frequency distributions of $M$. helena are presented in Fig. 7. The mean lengths-atage of males and females showed that there were no significant differences for any of the age classes (2sample $t$-test, $\mathrm{p}=0.259$ ). Overall, the age frequency distributions of males and females did not differ significantly (Kolmogorov-Smirnov 2-sample test, $\mathrm{p}>0.05)$.

Significant linear relationships were found between $\mathrm{OL}$ and fish age $(t)\left(\mathrm{OL}=2.636+0.22 t ; \mathrm{R}^{2}=\right.$ $0.491, \mathrm{p}=0.001)$ and between $\mathrm{OM}$ and $t(\mathrm{OM}=$ $\left.-0.002+0.0014 t_{;} \mathrm{R}^{2}=0.744, \mathrm{p}=0.001\right)$.

The VBGF for the sampled population had the following parameters: $L_{\infty}=162.7 \mathrm{~cm}(\mathrm{SE}=0.489), k=$ $0.089 \mathrm{yr}^{-1}(\mathrm{SE}=0.003)$ and $t_{0}=-0.660 \mathrm{yr}(\mathrm{SE}=0.219)$ $\left(\mathrm{R}^{2}=0.928\right)$. The estimated non-linear least squares parameters for the total sample, males and females are given in Table 2. A significant difference was found between the von Bertalanffy growth parameters of males and females, using a Hotelling's $T^{2}$-test $\left(T^{2}=231.4>T_{0}^{2}=11.97\right)$, with females growing at slightly slower rate than males. The calculated asymptotic length value was higher than the maximum observed length $(121 \mathrm{~cm})$. According to the von Bertalanffy growth equation, obtained longevity $\left(A_{0.95}\right)$ is estimated at 35 yr. Furthermore, during the first $4 \mathrm{yr}$ of its life, $M$. helena grows rapidly; afterwards, its growth rate slows down considerably.

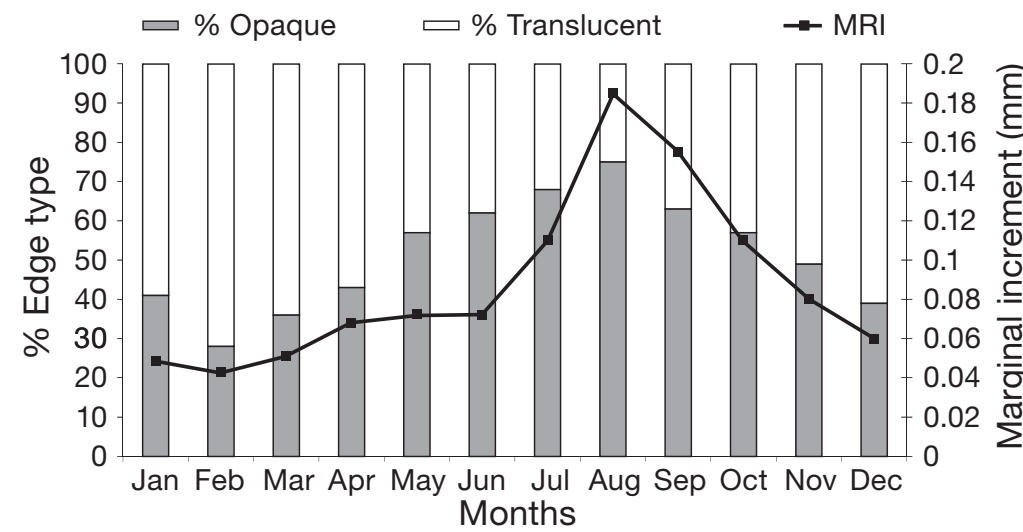

Fig. 6. Muraena helena. The monthly frequency of opaque and translucent margins and ( $\boldsymbol{\square})$ the monthly means of marginal increment (MRI) of otoliths of Mediterranean moray eels from the Adriatic Sea

\section{Reproductive analysis}

All specimens above $78 \mathrm{~cm}$ TL were sexually mature. The smallest female with ovary containing ripe eggs had a TL of $68.6 \mathrm{~cm}$. According to the estimated data, length at $50 \%$ maturity was found to be $L_{50}=76 \mathrm{~cm}$ TL for females and $L_{50}=$ $79.0 \mathrm{~cm}$ TL for males. The percentage of mature males and females per length classes is shown in Fig. 8. GSI varied from 0.02 to 12.50 and varied significantly among seasons (1-way ANOVA, p < 0.05), namely between summer and autumn (Tukey Test, p < 0.05) (Fig. 4). GSI varied 
Table 1. Muraena helena. Length-at-age data for Mediterranean moray eels from the Adriatic Sea aged using otolith readings. Figures show the number of individuals classed by age within each length interval. TL = total length, W = weight

\begin{tabular}{|c|c|c|c|c|c|c|c|c|c|c|c|c|}
\hline $\begin{array}{l}\text { Length } \\
\text { interval }(\mathrm{cm})\end{array}$ & 2 & 3 & 4 & 5 & 6 & $\begin{array}{c}\text { Age }(y r) \\
7\end{array}$ & 8 & 9 & 10 & 11 & 12 & Total \\
\hline $25.5-28.4$ & 1 & & & & & & & & & & & 1 \\
\hline $28.5-31.4$ & 1 & & & & & & & & & & & 1 \\
\hline $31.5-34.4$ & & & & & & & & & & & & 0 \\
\hline $34.5-37.4$ & & & & & & & & & & & & 0 \\
\hline $37.5-40.4$ & & & & & & & & & & & & 0 \\
\hline $.40 .5-43.4$ & & 2 & & & & & & & & & & 2 \\
\hline $43.5-46.4$ & & & 1 & & & & & & & & & 1 \\
\hline $46.5-49.4$ & & & 1 & & & & & & & & & 1 \\
\hline $49.5-52.4$ & & 1 & 3 & & & & & & & & & 4 \\
\hline $.52 .5-55.4$ & & & 4 & & & & & & & & & 4 \\
\hline $.55 .5-58.4$ & & & 9 & & & & & & & & & 9 \\
\hline $58.5-61.4$ & & & 6 & 6 & & & & & & & & 12 \\
\hline $61.5-64.4$ & & & 1 & 10 & 4 & & & & & & & 15 \\
\hline $64.5-67.4$ & & & & 6 & 8 & & & & & & & 14 \\
\hline $67.5-70.4$ & & & & 5 & 13 & 4 & & & & & & 22 \\
\hline $70.5-73.4$ & & & & 6 & 9 & 5 & 1 & & & & & 21 \\
\hline $73.5-76.4$ & & & & & 4 & 5 & & & & & & 9 \\
\hline $76.5-79.4$ & & & & 1 & 4 & 15 & & & & & & 20 \\
\hline $79.5-82.4$ & & & & 1 & & 7 & 4 & & & & & 12 \\
\hline $82.5-85.4$ & & & & & 1 & 6 & 4 & & & & & 11 \\
\hline $85.5-88.4$ & & & & & & 2 & 7 & & & & & 9 \\
\hline $88.5-91.4$ & & & & & & & 1 & 2 & & & & 3 \\
\hline $91.5-94.4$ & & & & & & & 5 & 3 & & & & 8 \\
\hline $94.5-97.4$ & & & & & & & & 1 & 2 & & & 3 \\
\hline $97.5-100.4$ & & & & & & & & 3 & 1 & & & 4 \\
\hline $100.5-103.4$ & & & & & & & & & 1 & & & 1 \\
\hline $103.5-106.4$ & & & & & & & & & 1 & 2 & & 3 \\
\hline $106.5-109.4$ & & & & & & & & & & & & 0 \\
\hline $109.5-112.4$ & & & & & & & & & & & & 0 \\
\hline $112.5-115.4$ & & & & & & & & & 1 & & & 1 \\
\hline $115.5-118.4$ & & & & & & & & & & & 1 & 1 \\
\hline $118.5-121.4$ & & & & & & & & & & 1 & & 1 \\
\hline Total & 2 & 3 & 25 & 35 & 43 & 44 & 22 & 9 & 6 & 3 & 1 & 193 \\
\hline$\%$ & 1.12 & 1.68 & 13.41 & 16.76 & 21.79 & 22.35 & 12.29 & 5.03 & 3.35 & 1.68 & 0.56 & 100 \\
\hline Mean TL (cm) & 29.5 & 44.3 & 55.7 & 65.8 & 70.2 & 78.1 & 86.4 & 94.9 & 102.0 & 110.3 & 118.0 & \\
\hline SD TL & 2.828 & 4.932 & 4.116 & 5.381 & 5.067 & 4.927 & 5.186 & 3.832 & 6.504 & 7.587 & 0.00 & \\
\hline Mean W (g) & 277.8 & 156.2 & 338.1 & 644.0 & 768.0 & 1018.1 & 1432.686 & 1933.5 & 2274.6 & 3460.0 & 3680.0 & \\
\hline SD W & 144.250 & 66.192 & 101.761 & 220.045 & 174.683 & 264.464 & 382.516 & 580.305 & 591.620 & 117.757 & 0.00 & \\
\hline
\end{tabular}

from 0.02 to 12.50 for females, and from 0.02 to 0.22 for males.

Histological examination of the gonads revealed that the Mediterranean moray eels in the Adriatic Sea mature in warmer months and spawn during the late summer. The autumn-winter period is their rest phase, when only individuals with cells in growth stage were observed. In July, males were found to be at their maturation stage (Fig. 9A). An increase of the number of mature spermatozoa was noted and low numbers of other germ cells. Immature males, with early spermatogonia, were found in the winter/spring period, as well as females with immature ovaries containing only primary growth stage oocytes. The ovaries of vitellogenic females showed numerous vitellogenic oocytes together with a small number of oocytes at the primary growth stage of development (Fig. 9B). These females were observed from February to May, while females with fully mature oocytes and post-ovulatory follicles were not recorded among histologically sampled individuals. However, females with ripe eggs were noticed during spring months on the field. Interestingly, in females, GSI values less than 1 corresponded to ovaries containing pre-vitellogenic primary oocytes. 


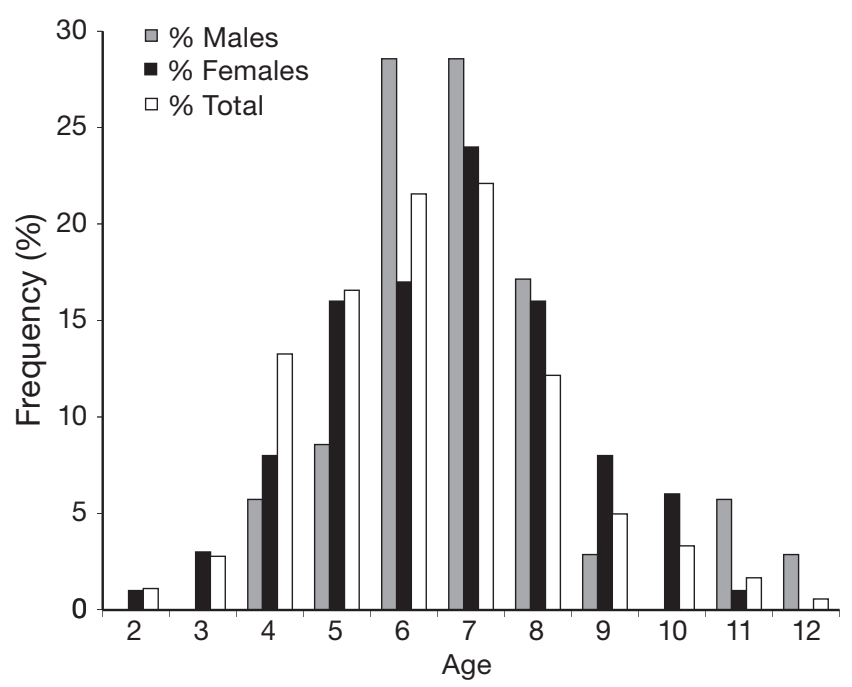

Fig. 7. Muraena helena. Age distributions of males, females and the total sample of Mediterranean moray eels from the Adriatic Sea

Table 2. Muraena Helena. Growth parameters $( \pm \mathrm{SE})$ for males and females and the total sample of Mediterranean moray eels from the Adriatic Sea, estimated by non-linear regression from otolith readings

\begin{tabular}{|lccc|}
\hline & $L_{\infty}(\mathrm{cm})$ & $k\left(\mathrm{yr}^{-1}\right)$ & $t_{0}(\mathrm{yr})$ \\
\hline Males & $163.6 \pm 0.628$ & $0.090 \pm 0.008$ & $-0.630 \pm 0.659$ \\
Females & $159.1 \pm 0.553$ & $0.089 \pm 0.003$ & $-0.887 \pm 0.279$ \\
Totals & $162.7 \pm 0.489$ & $0.089 \pm 0.003$ & $-0.660 \pm 0.219$ \\
\hline
\end{tabular}

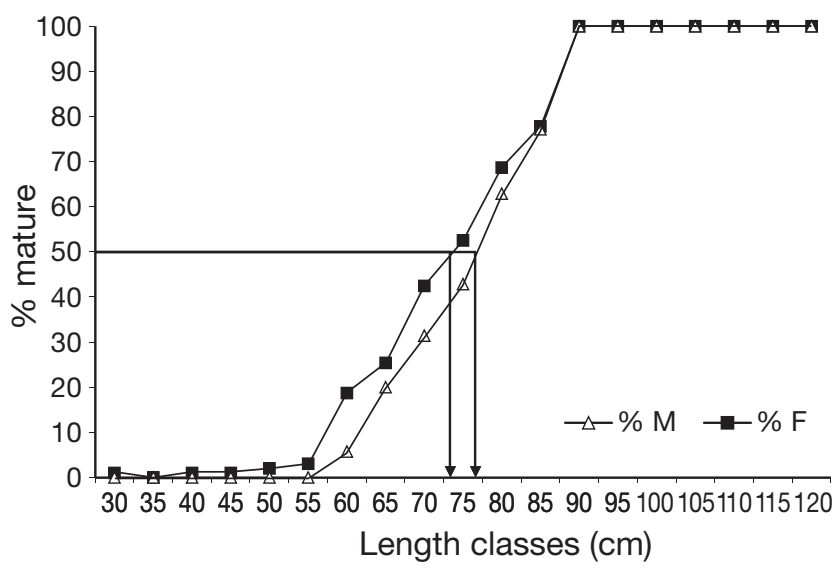

Fig. 8. Muraena helena. Length at $50 \%$ maturity of $(\Delta)$ male and (घ) female Mediterranean moray eels from the Adriatic Sea

\section{DISCUSSION}

As previously mentioned, there is a lack of the age data for most species of the Muraenidae family, and

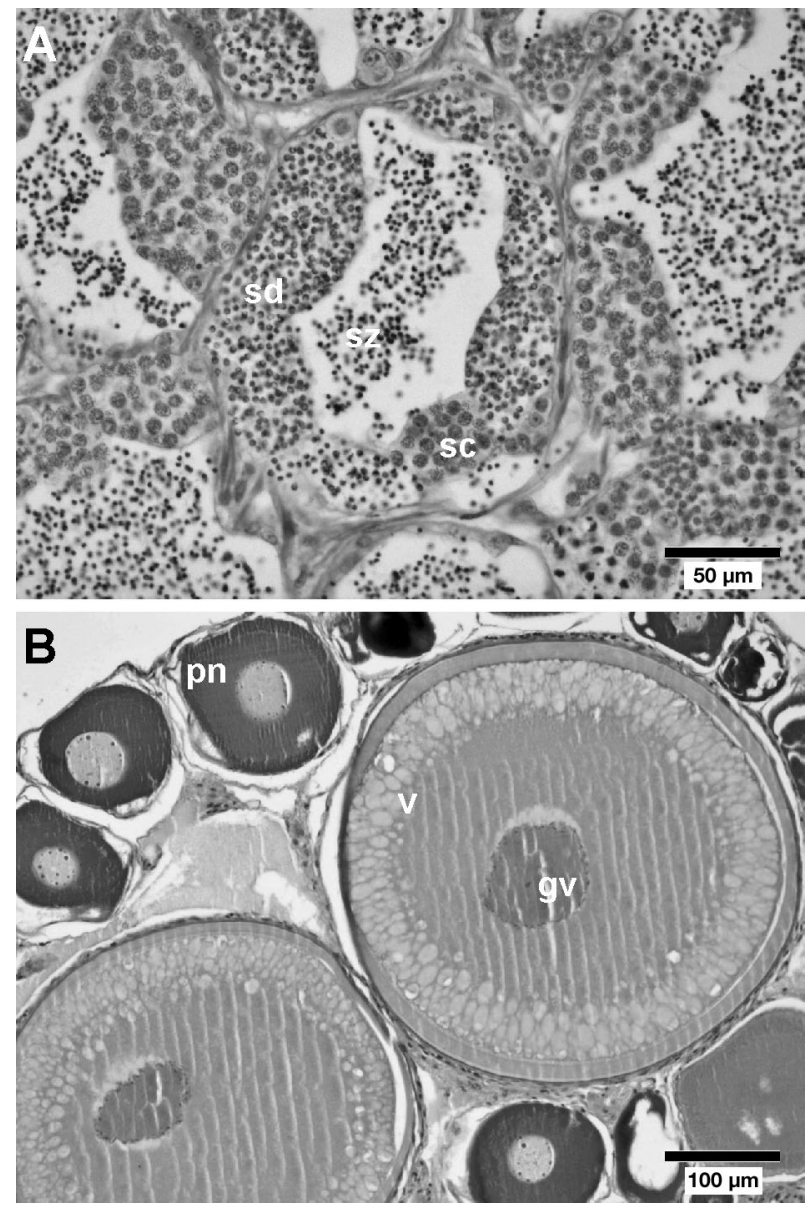

Fig. 9. Muraena helena. Photomicrographs of histological sections of gonads. (A) Testis showing seminiferous lumen filled with spermatozoa (sz) with spermatocytes (sc) and spermatids (sd) lining the lobular germinal epithelium. (B) Ovary with oocytes in different developmental stages: perinucleolar (pn) and in advanced vitellogenic (v) stage with migratory germinal vesicle (gv)

in this study we decided to use otoliths, since they are the most frequently used hard part for fish ageing (Sparre \& Venema 1992). Muraena helena otoliths exhibited a well-defined and consistent mark pattern consisting of one opaque and one translucent zone. The present results showed that growth zones in otoliths of the Mediterranean moray eel are laid down annually, the opaque zone being generally deposited in summer, which corresponds to the observed spawning period, and the translucent zone in the autumn/winter period.

In general, otoliths of Muraena helena were determined to be valid structures for age and growth studies due to the great consistency among repeated age readings. However, determination of the first annulus was problematical, especially in older individuals. 
We tried to solve the problem by measuring the distance of each annual growth ring from the otolith nucleus. Results showed that the first growth ring (that corresponds to the fish's first year of life) can be determined as the first regular, continuous ring that is found at a similar distance from the otolith nucleus in the majority of otoliths. In $<10 \%$ of the specimens, 1 or 2 rings were visible at different distances to the otolith nucleus, closer than the determined first growth ring. However, these rings were usually irregular and incomplete. Their formation could be attributed to a very long pelagic larval interval (around $1 \mathrm{yr}$ ), different migration routes chosen by each specimen and oceanographic conditions during settlement from pelagic to benthic phase.

According to our results, ages of the Muraena helena from the Adriatic Sea ranged from 2 to $12 \mathrm{yr}$. The only other investigation of $M$. helena age comes from the Canary Islands, where Jiménez et al. (2007) reported ages for $M$. helena and the closely related species $M$. augusti from 3 to $15 \mathrm{yr}$ and 4 to $12 \mathrm{yr}$, respectively. Our results are also consistent with those obtained for conger eel Conger conger (family Congridae) from the Atlantic Iberian waters (Correia et al. 2009) and Irish coastal waters (Sullivan et al. 2003). C. conger is an anguilliform fish and thus related to $M$. helena; moreover, current investigation of the biology of both species points to similar reproductive strategy, age and growth patterns as well as similar trophic ecology in the Adriatic Sea. Based on these findings, we can assume that the average maximum age of both species is up to 12-15 yr.

The length of Muraena helena caught by bottom longlines in the Adriatic Sea ranged from 27.5 to $121.0 \mathrm{~cm}$, while the length range of the Canary Islands specimens, collected using bottom longlines, bottom traps and hand lines, was from 41.9 to $134.0 \mathrm{~cm}$ (Jiménez et al. 2007). We consider it is likely that the use of different gears in our study biased the size of sampled individuals. Shorter individuals could not be captured due to the hook size and the small length range is probably a consequence of the operational depth of the gear used. Studies investigating gear selectivity revealed that conger eel individuals caught by bottom longlines are longer than those caught by other gears (Hood et al. 1988, Sullivan et al. 2003). Unlike conger eels, which can be seen swimming over the bottom, moray eels rarely leave their holes, maintaining high site fidelity (Böhlke et al. 1989) and are thus less susceptible to other fishing gears, like trammel nets. So, for practical purposes, bottom longlines are the only fishing gear which allows collection of large numbers of this species.
Both females and males of Muraena helena were captured in Adriatic coastal waters at depths of around 30 to $80 \mathrm{~m}$ although females dominated in the total sex ratio $(0.35: 1.00)$. The majority of sampled males were taken from the deeper sites located at a greater distance from the coastline. Jiménez et al. (2007) also reported predominance of females for moray eels off the Canary Islands. Sex ratio fluctuation, with male predominance in deeper waters, is also known for Conger conger in the Sardinian channel (Cau \& Manconi 1983). In contrast, in the case of the American conger eel C. oceanicus both sexes were captured by longline in inshore waters (Hood et al. 1988), as in our study. However, since M. helena males occur in deeper water, our sex ratio could be partially the result of fishermen lowering longlines to preferred depths and due to bathymetric sexual segregation.

The Mediterranean moray eels of the Adriatic Sea showed negative allometric growth and $b$ values were significantly different from 3 for both sexes. However, the value of $b$ determined by Jiménez et al. (2007) for Muraena helena from the Canary Islands was 3.314, indicating positive allometric growth. This difference could be due to different sample sizes (they collected 750 individuals from commercial catches using different fishing gears at different fishing ports in the Canary Islands), but it could also reflect the sex ratio and percentage of mature individuals in the total analyzed sample (Ricker 1975). The relative CF for $M$. helena in the present study was lowest in the winter and highest in the spring months, most likely as a consequence of sea temperature changes that affect metabolic rates. Furthermore, lower winter $\mathrm{CF}$ values could be attributed to lower food availability and the mobilization of somatic energy reserves for reproductive development, as suggested for Conger conger by Sullivan et al. (2003).

Growth parameter estimates for Muraena helena from the Adriatic Sea gave results of $L_{\infty}=162.7 \mathrm{~cm}$, $k=0.089$ and $t_{0}=-0.660$. The obtained asymptotic length is higher than maximal length observed in sampled individuals. The mean lengths corresponding to first years of life are probably overestimated due to the lack of smaller specimens as a result of bottom longlines selectivity. Parameters of the VBGF for moray eels from Canary Islands were very similar to ours with $L_{\infty}=170.0 \mathrm{~cm}, k=0.078, t_{0}=-0.355$ and $L_{\infty}=105.9 \mathrm{~cm}, k=0.178, t_{0}=1.103$ for M. helena and $M$. augusti, respectively (Jiménez et al. 2007). It seems that both species, as well as Conger conger (Sbaihi et al. 2001, Sullivan et al. 2003, Correia et al. 
2009) have relatively slow growth and a prolonged life span. Population density, water temperature or the quantity of available food could affect growth of $M$. helena because of its restricted range of movement. The oldest sampled $M$. helena specimens were 11 and $12 \mathrm{yr}$ old, female and male respectively. We consider that the species' life span could be around $15 \mathrm{yr}$, which is supported by the estimated longevity value of 35 yr. Jiménez et al. (2007) estimated a lifespan of $38.1 \mathrm{yr}$ for their moray eel specimens aged from 3 to $15 \mathrm{yr}$. Longevity is a theoretical value based on parameters obtained by VBGF and is very sensitive to the sample size, so it can be far from the real life span; i.e. if organisms are large, the asymptotic length increases while the growth coefficient decreases, and if organisms present a large $k$ value, its asymptotic length is reached in a shorter period of time (Barr et al. 2008). Our VBGF estimates appear realistic values since moray eels are known to grow to large sizes up to $2 \mathrm{~m}$ (Jardas 1996) and have a relatively slow growth rate. For conger eels, Sbaihi et al. (2001) reported body growth increment of $10 \mathrm{~cm}$ $\mathrm{yr}^{-1}$, with the growth rate slowing down from year 10 upwards. This is in accordance with our findings, at least for the first $5 \mathrm{yr}$ of life.

Comparison of the female GSI values with the histological examination of the ovaries showed that smaller GSI $(<1)$ corresponds to the presence of previtellogenic primary oocytes. This observation was also reported by Hood et al. (1988) and Sbaihi et al. (2001) for the related species Conger oceanicus and C. conger, respectively. Based on the present results, we suppose that Muraena helena spawns in summer with peak in July, probably with size at maturity at around $79 \mathrm{~cm}$ and at 6 to $8 \mathrm{yr}$ of age. A similar size and age at first maturity of around $75 \mathrm{~cm}$ and $7.1 \mathrm{yr}$, respectively, were reported for $M$. helena by Jiménez et al. (2007) in the Canaries. However the spawning period was prolonged from January to July, which is probably related to the higher sea temperatures in the Canary Islands compared to the Adriatic Sea.

The majority of specimens collected were either immature or in a developing stage. Ovaries contained either oocytes in a pre-vitellogenic or in early vitellogenic stage and ripe females with mature hydrated oocytes were never found. The lack of fully mature, ready to spawn individuals in the inner waters indicates that moray eels do not reach full sexual maturity in the coastal waters of the south Adriatic Sea. In females in the present study, increasing GSI was attributed to deposition of adipose tissue surrounding the oocytes. The same phenomenon was recorded for Conger conger (Sullivan et al. 2003,
Correia et al. 2009). However, some morphophysiological changes observed in wild conger eels related to advanced stages of sexual maturation, like regression of the digestive tract, calcium teeth and bone resorption or body coloration (Cau \& Manconi 1983, Hood et al. 1988), were not found in Muraena helena in our study.

Some uncertainties related to the range of ages in which $50 \%$ of individuals firstly become matured appeared in the present study. Similar uncertainties are also reported for the European conger eel, which is believed to reach sexual maturity at the age of 5 to 15 yr (Correia et al. 2009 and papers therein). The wide ranges reported for both species may be due to the lack of specimens of moray and conger eels in a fully developed stage of maturity. The estimation of accurate maturity schedules requires accurate descriptions of stages of maturity, as well as basing estimates only on samples collected during the identified spawning season. Using females with fully developed oocytes in their ovaries to assess maturity and sampling during the spawning season, to reduce the possibility of confusing post-spawning females with immature or inactive females, has proven to give greater precision in size at maturity estimates (Arocha \& Bárrios 2009).

On the basis of data presented herein, we suggest that Muraena helena individuals reach sexual maturity at ages ranging from 3 to $10 \mathrm{yr}$ (when $100 \%$ of the population has reached maturity) and then they migrate to spawn in the south Adriatic Pit, at a depth below $600 \mathrm{~m}$, most likely in the summer. A similar scenario with migration towards the deep sea spawning areas was previously proposed for Conger conger (Cau \& Manconi 1983, Sullivan et al. 2003, Correia et al. 2009). The assumption of the south Adriatic Pit as the most likely spawning place of $M$. helena and $C$. conger in the Adriatic Sea is further supported by the length and otolith analyses of their leptocephali collected in that particular area (S. Matić-Skoko pers. obs.). Moreover, it should be taken into consideration that the nearest reported spawning ground for $C$. conger is in the Sardinian channel at a depth of around 600 to $800 \mathrm{~m}$ (Cau \& Manconi 1983), which seems too far away to be the spawning area for the moray and conger eel species of the Adriatic Sea.

In conclusion, more information about the reproductive biology (exact time and place of spawning, larval period duration, time of the settlement from pelagic to benthic habitats), population structure and distribution of Muraena helena in the Mediterranean and the Adriatic Sea is needed in order to improve scientific knowledge of this species and to inform 
fisheries management in Mediterranean coastal zones. Future studies should also attempt to estimate to what extent habitat conditions modify the growth pattern of resident moray eels and to incorporate juvenile growth into studies of adult population growth. Moreover, determination of ontogenetic feeding strategy of this predator fish together with its trophic status is needed to clarify its specific growth pattern and its position in complex littoral benthic communities.

Acknowledgements. We thank all those involved in the collection of material, particularly local fishers Mato Lujo, Mato Oberan and Hajro Turković and student Ivan Ban. Special thanks to Josipa Ferri for help in otolith readings and preparation of the manuscript. The present work was supported by the Ministry of Science, Education and Sport, Croatia through projects 275-0010501-0856 and 001-0013077-0844.

\section{LITERATURE CITED}

Abrams RW, Abrams MD, Schein MW (1983) Diurnal observations on the behavioral ecology of Gymnothorax moringa (Cuvier) and Muraena miliaris (Kaup) on a Caribbean reef. Coral Reefs 1:185-193

Arocha F, Bárrios A (2009) Sex ratios, spawning seasonality, sexual maturity, and fecundity of white marlin (Tetrapturus albidus) from the western central Atlantic. Fish Res 95:98-111

Barr EE, Cabello GM, Solis CEG, Boa AG, Gómez MP (2008) Growth of the Pacific jack Caranx caninus (Pisces: Carangidae) from the coast of Colima, México. Rev Biol Trop 56:171-179

Beamish RJ, Fournier DA (1981) A method for comparing the precision of a set of age determination. Can J Fish Aquat Sci 38:982-983

Beverton RJH, Holt SJ (1957) On the dynamics of exploited fish populations. Fishery investigations, Series 2, Vol 19. Ministry of Agriculture, Fishery and Food, UK

Bishop RE, Torres JJ (1999) Leptocephalus energetics: metabolism and excretion. J Exp Biol 202:2485-2493

Böhlke EB, McCosker JE, Böhlkem JE (1989) Family Muraenidae. In: Böhlke EB (ed) Fishes of the western North Atlantic, Part 9, Vol 1 Orders Anguilliformes and Saccopharyngiformes. Mem Sears Found Mar Res, New Haven, CT, p 104-206

> Carr MH, Hixon MA (1995) Predation effects on early postsettlement survivorship of coral-reef fishes. Mar Ecol Prog Ser 124:31-42

Cau A, Manconi P (1983) Sex ratio and spatial displacement in Conger conger (L. 1758). Rapp P-V Reun Comm Int Explor Sci Mer Mediterr 28:93-96

> Chang WB (1982) A statistical method for evaluating the reproducibility of age determinations. Can J Fish Aquat Sci 39:1208-1210

> Correia AT, Manso S, Coimbra J (2009) Age, growth and reproductive biology of the European conger eel (Conger conger) from the Atlantic Iberian waters. Fish Res 99: 196-202

Ferraris CJ (1985) Spawning in Gymnothorax. Copeia 1985: 518-520

Fishelson L (1992) Comparative gonad morphology and sexuality of the Muraenidae (Pisces, Teleostei). Copeia
1992:197-209

Göthel H (1992) Fauna marina del Mediterráneo. Ediciones Omega, Barcelona

Grier HJ (1981) Cellular organization of the testis and spermatogenesis in fishes. Am Zool 21:345-357

Hixon MA (1991) Predation as a process structuring coral reef fish communities. In: Sale PF (ed) The ecology of fishes on coral reefs. Academic Press, San Diego, CA, p 475-508

Hood PB, Able KW, Grimes CB (1988) Biology of the conger eel Conger oceanicus in the Mid-Atlantic Bight. Mar Biol 98:587-596

Jardas I (1996) Adriatic ichthyofauna. Školska knjiga, Zagreb

> Jiménez S, Schönhuth S, Lozano IJ, González JA, Sevilla RG, Diez A, Bautista JM (2007) Morphological, ecological and molecular analyses separate Muraena augusti from Muraena helena as a valid species. Copeia 2007: 101-113

Matić-Skoko S, Stagličić N, Pallaoro A, Kraljević M, Dragičević B, Tutman P, Dulčić J (2009) Inventory of coastal fisheries resources and recommendation for sustainable costal fisheries in Vis aquatorium. In: Project 'Coast' 8211. Conservation and Sustainable Use of Biodiversity in the Dalmatian Coast through Greening Coastal Development, UNDP Institute of Oceanography and Fisheries, Split

> Mehta RS, Wainwright PC (2007) Biting releases constraints on moray eel feeding kinematics. J Exp Biol 210:495-504

> Mehta RS, Wainwright PC (2008) Functional morphology of the pharyngeal jaw apparatus in moray eels. J Morphol 269:604-619

O'Sullivan SO, Moriarty C, FitzGerald RD, Davenport J, Mulcahy MF (2003) Age, growth and reproductive status of the European conger eel, Conger conger (L.) in Irish coastal waters. Fish Res 64:55-69

> Palazón-Fernandez JL, Potts JC, Manooch CS III, Sarasquete C (2010) Age, growth and mortality of the toadfish, Halobatrachus didactylus (Schneider, 1801) (Pisces: Batrachoididae), in the Bay of Cádiz (southwestern Spain). Sci Mar 74:121-130

Randall JE, Golani D (1995) Review of the moray eels (Anguilliformes, Muraenidae) of the Red Sea. Bull Mar Sci 56:849-880

Reece JS, Bowen BW, Smith DG, Larson A (2010) Molecular phylogenetics of moray eels (Muraenidae) demonstrates multiple origins of a shell-crushing jaw (Gymnomuraena, Echidna) and multiple colonizations of the Atlantic Ocean. Mol Phylogenet Evol 57:829-835

Ricker WE (1975) Computation and interpretation of biological statistics of fish populations. Bull Fish Res Board Can 191:1-382

Sbaihi M, Fouchereau-Peron M, Meunier F, Elie P and others (2001) Reproductive biology of conger eel from the south coast of Brittany, France and comparison with the European eel. J Fish Biol 59:302-318

Smith DG, Böhlke EB (1990) Muraenidae. In: Quero JC, Hureau JC, Karrer C, Post A, Saldanha L (eds) Check-list of the fishes of the eastern tropical Atlantic (CLOFETA), Vol 2. JNICT, Lisbon; SEI, Paris; and UNESCO, Paris, p 136-148

Sparre P, Venema SC (1992) Introduction to tropical fish stock assessment. Part 1. FAO Fisheries Technical Paper, Food and Agriculture Organization, Rome

Taylor CC (1960) Temperature, growth and mortality-the Pacific cockle. J Cons Int Explor Mer 26:117-124

Wallace R, Selman K (1981) Cellular and dynamic aspects of oocyte growth in teleosts. Am Zool 21:325-343 